\title{
Optimizing combination therapy in the management of hypertension: the role of the aliskiren, amlodipine, and hydrochlorothiazide fixed combination
}

\author{
This article was published in the following Dove Press journal: \\ Integrated Blood Pressure Control \\ 15 June 2013 \\ Number of times this article has been viewed
}

\author{
Michael B Hovater' \\ Edgar A Jaimes ${ }^{1,2}$ \\ 'Division of Nephrology, Department \\ of Medicine, University of Alabama \\ at Birmingham, Birmingham, AL, USA; \\ ${ }^{2}$ Department of Veterans Affairs \\ Medical Center, University of Alabama \\ at Birmingham, Birmingham, AL, USA
}

\begin{abstract}
High blood pressure is the leading risk factor for death and disability worldwide, and the prevalence is increasing. Effective treatment decreases the risk of adverse events in proportion to blood pressure reduction. Combination antihypertensive therapy reduces blood pressure promptly and effectively. Single-pill combinations reduce the pill burden and improve adherence, efficacy, and tolerability of treatment compared with single drug pills. A significant portion of the hypertensive population will require three drugs for adequate control. The singlepill combination of aliskiren, amlodipine, and hydrochlorothiazide is based on complementary mechanisms of action. Clinical trials have shown it to be a safe and effective treatment for hypertension. This combination is a reasonable choice in clinical practice for patients with hypertension that requires three drugs for effective treatment.
\end{abstract}

Keywords: aliskiren, amlodipine, hydrochlorothiazide, Amturnide, hypertension, combination

\section{Introduction}

High blood pressure is the number one risk factor for death and disability worldwide. ${ }^{1}$ Approximately $30 \%$ of the population has hypertension, and the prevalence is further increasing. ${ }^{2,3}$ Poorly controlled hypertension causes cardiovascular disease, resulting in increased risk of stroke, ${ }^{4-6}$ heart disease (including myocardial infarction, heart failure, and arrhythmias), ${ }^{4-7}$ and kidney disease. ${ }^{6,8,9}$ The risk is increased in individuals with comorbidities such as diabetes, chronic kidney disease, and coronary artery disease. ${ }^{10-13}$ Reduction of elevated blood pressure greatly reduces the burden of vascular disease, end-organ damage, and death. ${ }^{7,13}$

There are a number of safe and effective antihypertensive medications available. A wide variety of combinations and doses have been studied. Despite the effective therapies available, there is a concerning number of patients with poorly controlled hypertension. The Centers for Disease Control recently reported that among those with hypertension in the United States, an alarmingly high 53.5\% did not have their blood pressure controlled. ${ }^{3}$ This highlights an opportunity for expanded efforts help patients achieve hypertension control with a goal of improving the quality and length of their lives.

There are a number of reasons why blood pressure is often poorly controlled. A small number of cases are due to truly resistant hypertension (often due to coexisting medical conditions or secondary causes). ${ }^{14,15}$ Patient factors have long been recognized as part
Correspondence: Edgar A Jaimes

The University of Alabama at Birmingham, ZRB 637, 1720 2nd Ave South,

Birmingham, AL 35294, USA

Tel +l 2059340544

$\mathrm{Fax}+\mathrm{I} 2059756288$

Email ejaimes@uab.edu 
of the problem. Some patients are unaware of their hypertension or unwilling to undergo treatment. ${ }^{3}$ Among treated patients, there are issues with patient adherence, poor understanding of the problem, and limited financial resources. ${ }^{16,17}$ Systemic factors, such as limited access to health care, lack of insurance, inability to get an appointment, and limited access to medications are frequently debated. ${ }^{3,18,19}$

Physician factors that have a negative effect on blood pressure control, including poor communication and therapeutic inertia, are becoming more evident. ${ }^{20,21}$ Therapeutic inertia is the reluctance of the health care provider to add new medications or to increase the dosage when goals are not met. Okonofua et $\mathrm{al}^{21}$ addressed the role of therapeutic inertia in poorly controlled hypertension by examining medical records of physicians participating in the Hypertension Initiative medical record audit and feedback program. They examined the medical records of over 7000 patients who had seen a physician at least four times during the course of a year and had a blood pressure greater than 140/90. They found that blood pressure medications were not changed in $86.9 \%$ of encounters between patients and doctors in which the blood pressure was elevated. These findings highlight the role that provider inertia has on the poor rates of blood pressure control and the need for novel strategies to improve treatment of hypertension.

Among people who are treated for hypertension, a minority will achieve blood pressure control on a single drug, ${ }^{22}$ while the large majority will require multiple drugs to achieve adequate blood pressure control. In a number of large randomized-controlled trials, three or more medications were needed to achieve adequate blood pressure control for most patients. ${ }^{23-27}$ Fixed-dose combination antihypertensive therapy was first introduced into treatment in the 1950s. The first triple combination pill was introduced in the 1960s with the combination drug Ser-Ap-Es, a combination of reserpine, hydralazine, and hydrochlorothiazide. ${ }^{28,29}$ The initial experience and results were favorable. In fact, Ser-Ap-Es was the number one selling branded antihypertensive in the $1960 \mathrm{~s} .{ }^{28}$ However, and despite encouraging initial results, combination therapy fell out of favor as sequential monotherapy gained popularity.

Some authorities and experts in the field promoted the idea that hypertension could be successfully controlled if the agent selected targeted the correct pathway. The initial drug chosen was titrated up to maximal dose before another agent was added. Sporadic cases are seen where a specific cause of high blood pressure can be identified and targeted. However, the pathophysiology of hypertension is multifactorial, making monotherapy less effective. Moreover, compensatory mechanisms often offset the body's response to a single agent. Clinical experience has shown and trials have validated limited blood pressure reduction when any single agent is used alone. A meta-analysis of 354 randomized trials found that the mean placebo-adjusted blood pressure reduction from a single agent used as monotherapy was $9.1 \mathrm{mmHg}$ systolic and $5.5 \mathrm{mmHg}$ diastolic. ${ }^{30}$ The conclusion from this analysis was that combination therapy increased efficacy and reduced adverse effects of hypertension therapy as compared with monotherapy.

In recent years, there has been a resurgence of combination therapy on the basis of numerous trials showing efficacy and tolerability with improved adherence. ${ }^{31,32}$ There is a growing appreciation for the multiple factors contributing to hypertension, including genetic factors, dietary and environmental factors, and multiple physiologic pathways involved. Both the renin-angiotensin-aldosterone system (RAAS) and the sympathetic nervous system play major roles in regulating blood pressure. RAAS and the sympathetic nervous system are involved at different levels in the systemic regulation of blood pressure through their effects on cardiac performance, vascular tone, and the body's sodium and water balance. This makes the use of a combination that blocks multiple pathways a logical strategy for blood pressure control.

Recent analysis of data from the Valsartan Antihypertensive Long-term Use Evaluation (VALUE) trial indicates that the time required for blood pressure control is an important factor in clinical outcomes. Patients who achieved blood pressure control within the first month of treatment (independent of treatment group) had significantly fewer cardiovascular events and better survival. ${ }^{33}$ Based on the current knowledge about the pathophysiology of hypertension, it is clear that less time spent with elevated blood pressure is better for the patient. Increased time spent with elevated blood pressure results in worse endothelial injury and also increases the risk for cardiovascular and renal disease.

Recent trials demonstrate that combination therapy helps to achieve blood pressure control faster than monotherapy. The Simplified Treatment Intervention to Control Hypertension trial in Canada evaluated the effectiveness of a simplified algorithm to treat hypertension using a singlepill combination (angiotensin converting enzyme [ACE] inhibitor or angiotensin receptor blocker [ARB] combined with hydrochlorothiazide) as the initial step in the treatment of hypertension followed by up-titration and the addition of a calcium channel blocker. The simplified algorithm using 
initial combination therapy was more likely to achieve blood pressure control at 6 months than conventional guidelines that include initial monotherapy (Canadian Health Education Program guidelines). ${ }^{34}$

Evidence has continued to grow that combination therapy is often required for effective blood pressure control. Combination therapy has advantages for initiation of treatment, particularly in patients at higher risk due to significantly elevated blood pressure and/or comorbidities. A large portion of patients with hypertension will require three or more drugs to effectively control blood pressure. A single-pill combination is preferred whenever possible to simplify the regimen for the patient and to increased adherence. Physiologic synergy of complementary drugs increases the effectiveness of fixed-dose combination antihypertensive therapy.

\section{Overview of pharmacology of aliskiren, amlodipine, and hydrochlorothiazide and rationale for combination \\ Amlodipine}

The calcium channel blockers are a chemically diverse group of medications that target the L-type voltage-dependent calcium channel, stopping the influx of calcium into cells. In vascular smooth muscle cells, this causes vasodilation and a resultant decrease in systemic blood pressure. ${ }^{35}$ The three main classes of calcium channel blockers are dihydropyridines, phenylalkylamines, and benzothiazepines. Dihydropyridines are based on the chemical structure of pyridine and have a relatively high vascular selectivity. Amlodipine is a long-acting dihydropyridine approved for use as an antihypertensive by the United States Food and Drug Administration (FDA) in 1996.

In addition to vasodilation related to decreased contraction of vascular smooth muscle cells, amlodipine has a number of other mechanisms that may be physiologically and therapeutically relevant, although the relative contributions of individual pathways to the overall clinical impact of amlodipine is controversial. ${ }^{36}$ Calcium signaling is involved in a number of cellular pathways in the vasculature including cell proliferation and migration necessary for vascular hyperplasia. At physiologic $\mathrm{pH}$, amlodipine is in a charged state, which gives amlodipine a strong lipid affinity. This lipophilic property places the drug in close proximity to the calcium channels in the lipid bilayer and helps account for the long half-life of the drug.
Amlodipine's charged state and lipid affinity may also have additional therapeutic effects by reducing oxidative and nitrosative stress through calcium independent mechanisms. In the lipid bilayer, amlodipine is able to inhibit aggregation of oxidized low-density lipoproteins, an important step in the formation of atherosclerotic plaques. ${ }^{37}$ It can block lipid peroxidation and propagation of free radicals by acting as an antioxidant, donating its proton to quench free radical reactions. ${ }^{38-41}$ In addition, it increases nitric oxide formation and decreases the formation of peroxynitrite..$^{35,36,42}$

\section{Hydrochlorothiazide}

Hydrochlorothiazide has been available since the 1950s and is one of the most widely used antihypertensive medications prescribed in the United States. Its use has evolved over the years. Initially it was prescribed in the range of $100 \mathrm{mg}$ per day. In the current era, it is commonly prescribed in the 12.5-25 $\mathrm{mg}$ range. The use of hydrochlorothiazide soared after the first report of the Joint National Committee on Hypertension. The report called for a stepped-care approach for the treatment of hypertension, initiating therapy with a small dose of a single antihypertensive drug, increasing the dose of that drug, and adding other drugs as needed. The report specifically stated, "The first step in the recommended program should ordinarily be a thiazide-type diuretic." ${ }^{43}$ A number of thiazides were listed including hydrochlorothiazide at the "small dose" of 50-100 mg. Use of a thiazide-type diuretic in the United States became almost synonymous with hydrochlorothiazide. Subsequent reports of the Joint National Committee made similar recommendations for a "thiazide-type" diuretic as a front-line therapy. There is controversy about the selection of the best "thiazidetype" diuretic, with many pushing for a shift from the use of hydrochlorothiazide to chlorthalidone. ${ }^{44-47}$ At present, hydrochlorothiazide remains the predominant diuretic used in clinical practice and is the most commonly used diuretic in single-pill combination antihypertensive medications.

\section{Aliskiren}

Aliskiren is the first FDA-approved direct renin inhibitor available. ${ }^{48}$ Direct renin inhibition is an antihypertensive therapy that blocks the RAAS pathway at the rate-limiting step. Renin binds angiotensinogen and cleaves the $\mathrm{N}$-terminal portion to form angiotensin 1. ACE removes the $\mathrm{C}$-terminal portion to form the biologically active vasoconstrictor angiotensin 2. Aliskiren is a nonpeptide piperidine that binds with high affinity to the enzymatic site of renin, preventing hydrolysis of angiotensinogen and conversion 
to angiotensin 1. Aliskiren binds with high specificity to the enzymatic site of renin and generates a potent blockade. A $0.6 \mathrm{nmol} / \mathrm{L}$ concentration is sufficient for a $50 \%$ inhibition of renin. ${ }^{49}$

The RAAS pathway plays a major role in the regulation of blood pressure and increased activity contributes to increased blood pressure and the development and progression of hypertension. Increased RAAS activity contributes to increased vasoconstriction, sodium and water retention, increased cardiac contractility, cardiomyocyte hypertrophy, aldosterone synthesis, norepinephrine release, oxidative stress, and inflammation. ${ }^{50}$ Current therapeutics include ACE inhibitors that block the conversion of angiotensin 1 to angiotensin 2, ARBs that inhibit the type 1 ARBs, and mineralocorticoid receptor blockers that block the action of aldosterone at the aldosterone receptor.

Numerous randomized trials have demonstrated the beneficial effects of ACE inhibitors and ARBs in the clinical management of hypertension, diabetes, chronic kidney disease and proteinuria, myocardial infarction, and heart failure. Trials have established decreases in target organ damage and benefits in survival. ${ }^{51}$ Data is emerging in animal studies and in clinical trials supporting the benefits of aliskiren. ${ }^{52-55}$ The questions remain: how will aliskiren compare with ACE inhibitors and ARBs, and could aliskiren be a better therapeutic option? ${ }^{51,56,57}$

ACE inhibitors and ARBs only provide a partial blockade of the RAAS pathway. With ACE inhibitors and ARBs compensatory mechanisms increase plasma renin concentration (PRC) and plasma renin activity (PRA). There are non-ACE pathways for conversion of angiotensin 1 to angiotensin 2 through cathepsins and tonins. ${ }^{58,59}$ Angiotensin 2 levels gradually rise with long-term ACE inhibitor therapy, a phenomenon known as angiotensin 2 escape. ARBs fail to block the production of angiotensin 1 and angiotensin 2 , and induce a compensatory increase in PRC and PRA. The use of ARBs causes an initial decrease in aldosterone levels by blocking its synthesis in the zona glomerulosa of adrenal glands. With long-term use, $30 \%-40 \%$ of patients experience aldosterone breakthrough with gradual rise in aldosterone levels. ${ }^{60}$

It is not clear whether angiotensin 2 escape and aldosterone breakthrough have major clinical effects. More complete RAAS blockade gives a direct renin inhibitor a theoretical benefit over ACE inhibitors and ARBs. Dual blockade of the RAAS with a combination of an ACE inhibitor and an ARB was purposed as a way of avoiding the angiotensin 2 escape. Aliskiren blocks the first and rate-limiting step in RAAS, providing more complete blockade than ACE inhibitor or ARB alone. Aliskiren decreases PRA and levels of circulating angiotensin 1 and angiotensin 2 .

The Ongoing Telmisartan Alone and in Combination with Ramipril Global Endpoint Trial (ONTARGET) evaluated cardiovascular morbidity and mortality in high-risk adults taking an ACE inhibitor and ARB alone and in combination. The combination compared with either drug alone resulted in increased hypotension, syncope, and renal dysfunction without any cardiovascular benefit. ${ }^{61}$ The ALiskiren Trial In Type 2 diabetes Using cardio-renal Disease Endpoints (ALTITUDE) trial ${ }^{62}$ evaluated the addition of high-dose aliskiren (300 mg) or placebo to ongoing ACE inhibitor or ARB therapy in patients with type 2 diabetes and chronic kidney disease or cardiovascular disease. The primary endpoint measured was a comprised of death, cardiovascular event, or renal event. The trial was stopped early after an interim analysis revealed an increase in events in patients assigned to aliskiren. The composite endpoint was reached in $18.3 \%$ of patients assigned to aliskiren, compared to $17.1 \%$ of patients assigned to placebo. Data from the ONTARGET and ALTITUDE trials suggest that combination RAAS blockade may be harmful at high doses in high-risk patients. The results do not support the addition of aliskiren to ACE inhibitor or ARB therapy at this time. These trials do not speak to the role of aliskiren as the sole RAAS-blocking agent or to the role of aliskiren combination with other agents.

\section{Rationale for combination}

The attractiveness of combination antihypertensive therapy lies in the varied mechanisms of action by which the drugs exert their effects. Combining therapeutic agents that address different physiologic pathways that contribute to hypertension improves efficacy and tolerability of antihypertensive treatment. ${ }^{63-65}$ The combination of aliskiren (a direct renin inhibitor), amlodipine (a calcium channel blocker), and hydrochlorothiazide (a diuretic) is based on the complementary mechanisms of action of the different components. ${ }^{66}$

Direct renin inhibitors block RAAS at the initial step, leading to a reduction in PRA, angiotensin 1, and angiotensin 2, which results in reduced vasoconstriction. Calcium channel blockers cause vascular smooth muscle cells to relax, causing vasodilatation. Thiazide diuretics block the renal sodium chloride cotransporter, leading to sodium and water excretion and reduced plasma volume. As a result of sodium depletion and reduced plasma volume, thiazide diuretics activate RAAS and increase PRA. The 
compensatory increase in PRA with thiazides is offset by combination with a direct renin inhibitor. ${ }^{67}$ The most common adverse event reported with a calcium channel blocker is edema, which is partially offset by combination with a diuretic. ${ }^{67,68}$ The addition of aliskiren to an antihypertensive regimen with amlodipine reduced edema in a crossover study. ${ }^{68}$ The potent vasodilatation associated with dihydropyridine calcium channel blockers triggers compensatory activation of RAAS. The antihypertensive effect of dihydropyridine calcium channel blockers when used as monotherapy is reduced by RAAS activation. Thiazide diuretics cause potassium wasting, which is partially negated by combination with a direct renin inhibitor; combination with a direct renin inhibitor also increases the blood pressure-lowering efficacy. ${ }^{67}$

While aliskiren, amlodipine, and hydrochlorothiazide are all effective as monotherapy, overwhelming evidence now supports that combination therapy with complementary antihypertensive classes produces more effective and faster blood pressure reductions than monotherapy. ${ }^{63,69-73}$ When triple therapy is required, the European Society of Hypertension guidelines recommend a combination with a RAAS-blocking agent, a calcium channel blocker, and a diuretic. ${ }^{74}$ There is a theoretical benefit to choosing a triple combination with a direct renin inhibitor instead of an ACE inhibitor or an ARB. A combination that includes a direct renin inhibitor would be expected to lower angiotensin 2 levels and renin activity, and may have additional benefits independent of the blood pressure-lowering effects. However, clinical data is not currently available directly comparing triple combination with an ACE inhibitor or ARB versus triple combination with a direct renin inhibitor.

\section{Clinical efficacy}

The combination of aliskiren, amlodipine, and hydrochlorothiazide has been shown to effectively lower blood pressure in short-term and long-term trials. However, these trials were not of long enough duration and did not have the power to demonstrate a reduction in target organ damage or mortality. The clinicaltrials.gov database contains four trials of the combination drug aliskiren, amlodipine, and hydrochlorothiazide. The FDA approved the combination drug under the trade name Amturnide (Novartis International AG, Basel, Switzerland) after data from a short-term efficacy trial demonstrated effective blood pressure reduction over 8 weeks and a long-term safety study demonstrated safety over 54 weeks. ${ }^{67,75}$ Both trials have now been published for in peer-review journals. A third trial has been published evaluating the combination drug in minority patients with stage 2 hypertension. ${ }^{76,77}$ Results of the fourth trial have not been published at the time this review was written.

In a short-term, 8-week study, blood pressure control reduction with the triple combination of aliskiren, amlodipine, and hydrochlorothiazide was compared with the dual combinations of aliskiren and hydrochlorothiazide, aliskiren and amlodipine, and hydrochlorothiazide and amlodipine. ${ }^{75}$ In this study, 1191 patients were randomized to receive the triple combination or one of the three dual combinations in a double-blind fashion. Participants were started on the low-dose combination for 4 weeks and force titrated to the high-dose combination for 4 weeks. The triple combination provided statistically significant blood pressure reductions and greater blood pressure control rates at 4 and 8 weeks. The combinations were well tolerated. and the adverse events in all four groups were comparable. ${ }^{75}$

A long-term 28- and 54-week open-label study was conducted to evaluate the safety of the combination of aliskiren, amlodipine, and hydrochlorothiazide. ${ }^{67}$ The study enrolled 635 participants with stage 2 hypertension (blood pressure greater than or equal to $160 / 100 \mathrm{mmHg}$ ), and 564 entered the treatment phase. The first 206 participants that completed 28 weeks were asked to continue for an additional 6 months. Safety results are reviewed in the next section. Blood pressure was measured to evaluate efficacy. After four weeks of treatment, blood pressure decreased by $32.2 / 18.9 \mathrm{mmHg}$. The decreased blood pressure was sustained at week 28 and week 54 measurements. After 54 weeks of treatment, $77.2 \%$ of the overall study population achieved blood pressure control. In a subset of participants with severe hypertension, defined as blood pressure greater than or equal to $200 / 120 \mathrm{mmHg}$, blood pressure was reduced by a mean of $49.2 / 22.6 \mathrm{mmHg}$. At 54 weeks, $55.6 \%$ of patients with severe hypertension achieved blood pressure control. ${ }^{67}$

Additional assessment was done in a subset of participants with baseline and 28-week PRA, PRC, and aldosterone measurements. ${ }^{67}$ From baseline to 28 weeks, PRC increased 1545.8\%; however, overall PRA decreased by $41.8 \%$. Plasma aldosterone levels increased $44.5 \%$. Hydrochlorothiazide monotherapy causes a reduction in plasma volume, with a resultant increase in PRA. ${ }^{78,79}$ A previous study of the combination of hydrochlorothiazide and aliskiren showed an overall decrease in PRA compared with hydrochlorothiazide alone. ${ }^{80}$ A similar response with an overall decrease in PRA was seen when aliskiren was combined with hydrochlorothiazide and amlodipine. ${ }^{67}$ 
The AliSkiren Amlodipine HCTZ in Minority PatiENts with Stage II HyperTension (ASCENT) study was designed to evaluate safety and efficacy of the triple combination versus dual combination with aliskiren and amlodipine in self-identified minorities. ${ }^{76}$ It was a multicenter, 8-week, randomized, double-blind, active-controlled study with forced titration to maximal dose. Participants were randomized to triple combination therapy with aliskiren, amlodipine, and hydrochlorothiazide or dual therapy with aliskiren and amlodipine. Overall, 412 participants were randomized. After 8 weeks of treatment, $72.6 \%$ of minorities with stage 2 hypertension reached their blood pressure goal (defined as blood pressure less than $140 / 90 \mathrm{mmHg}$ ) with the triple combination, while only $53.2 \%$ were controlled with dual combination without hydrochlorothiazide. Mean blood pressure reduction with the triple combination was $36.5 / 15.1 \mathrm{mmHg}$, compared with $29.5 / 12.0 \mathrm{mmHg}$ with dual combination. A subgroup analysis was done to evaluate the effects in high-risk black participants with stage 2 hypertension and comorbidities of diabetes, cardiometabolic syndrome, or obesity. ${ }^{77}$ At the end of the study, blood pressure was reduced to goal in $75.4 \%$ of triple therapy-treated participants with diabetes compared with $55.8 \%$ of dual therapy-treated participants, $69.6 \%$ of triple therapy-treated participants with cardiometabolic syndrome compared with $50.7 \%$ of dual therapy-treated participants, and $68.4 \%$ of triple therapy-treated participants with obesity compared with $49.6 \%$ of dual therapy-treated participants. Triple combination with aliskiren, amlodipine, and hydrochlorothiazide was effective in reducing blood pressure, and the addition of hydrochlorothiazide provided an incremental benefit.

\section{Safety and tolerability}

The safety profile of the combination of aliskiren, amlodipine, and hydrochlorothiazide has been similar to the safety profile of the individual components. The safety and tolerability of amlodipine and hydrochlorothiazide are well known to most clinicians due to widespread use. Aliskiren is newer to the market, and most clinicians have limited experience. Aliskiren is generally well tolerated, as demonstrated in short-term and long-term trials. ${ }^{78,81-87}$ The most common adverse events reported were headache, nasopharyngitis, and diarrhea. Aliskiren has not been associated with cough like ACE inhibitors. A small number of patients have had angioedema with aliskiren. A study by Toh et a ${ }^{88}$ found that the incidence of angioedema for aliskiren (4.67 per 1000 person years) was similar to ACE inhibitors (4.38 per 1000 person years).
Murray et $a l^{67}$ recently reported safety and efficacy data from a 54-week open-label study. The most frequently reported adverse event was peripheral edema, a known effect of amlodipine, occurring in $9.4 \%$ of patients and leading to discontinuation in $2.3 \%$. Amlodipine when used as monotherapy has been reported to cause edema in $4.9 \%-34.4 \%$ of patients ${ }^{89}$ Hyperkalemia, defined as a serum potassium level during any study visit greater than $5.5 \mathrm{mmol} / \mathrm{L}$, was reported in $2.7 \%$ of study participants. ${ }^{67}$ Hypokalemia, defined as a serum potassium level during any study visit less than $3.5 \mathrm{mmol} / \mathrm{L}$, was reported in $11.7 \%$ of study participants. Hypotension was reported as an adverse event in $1.1 \%$ of participants, resulting in discontinuation of the drug in less than $1 \%$. Overall, the combination drug was well tolerated, most adverse effects were transient, and few adverse events required discontinuation of the drug. ${ }^{67}$

\section{Conclusion and place in therapy}

In clinical practice, a single-pill combination of aliskiren, amlodipine, and hydrochlorothiazide has a potential role. It is not indicated for initial therapy, but for escalation of therapy. It can be used as a second step in a patient partially controlled with two drugs or for rapid escalation in a patient started on initial monotherapy with markedly elevated blood pressure. A reasonable approach based on current data in most patients would be to start with a combination of a RAAS-blocking agent and a diuretic with escalation to triple therapy with the addition of a calcium channel blocker if blood pressure is not controlled with two drugs. The combination of aliskiren, amlodipine, and hydrochlorothiazide would be a reasonable choice for triple therapy.

\section{Acknowledgments}

This work was supported by grant funding from the National Institutes of Health (ES014948) and from the Office of Research and Development, Medical Research Service, Department of Veterans Affairs.

\section{Disclosure}

The authors report no conflicts of interest in this work.

\section{References}

1. Lim SS, Vos T, Flaxman AD, et al. A comparative risk assessment of burden of disease and injury attributable to 67 risk factors and risk factor clusters in 21 regions, 1990-2010: a systematic analysis for the Global Burden of Disease Study 2010. Lancet. 2013;380(9859):2224-2260.

2. Roger VL, Go AS, Lloyd-Jones DM, et al; for American Heart Association Statistics Committee and Stroke Statistics Subcommittee. Heart disease and stroke statistics - 2012 update: a report from the American Heart Association. Circulation. 2012;125(1):e2-e220. 
3. Centers for Disease Control and Prevention (CDC). Vital signs: awareness and treatment of uncontrolled hypertension among adults United States, 2003-2010. MMWR Morb Mortal Wkly Rep. 2012;61: 703-709.

4. Lewington S, Clarke R, Qizilbash N, Peto R, Collins R; for Prospective Studies Collaboration. Age-specific relevance of usual blood pressure to vascular mortality: a meta-analysis of individual data for one million adults in 61 prospective studies. Lancet. 2002;360(9349):1903-1913.

5. Clark CE, Taylor RS, Shore AC, Ukoumunne OC, Campbell JL. Association of a difference in systolic blood pressure between arms with vascular disease and mortality: a systematic review and meta-analysis. Lancet. 2012;379(9819):905-914.

6. Iseki K, Kimura Y, Wakugami K, et al. Comparison of the effect of blood pressure on the development of stroke, acute myocardial infarction, and end-stage renal disease. Hypertens Res. 2000;23(2):143-149.

7. Gu Q, Dillon CF, Burt VL, Gillum RF. Association of hypertension treatment and control with all-cause and cardiovascular disease mortality among US adults with hypertension. Am J Hypertens. 2010; 23(1):38-45.

8. Allison SJ. Hypertension: high systolic blood pressure is a major contributor to ESRD risk. Nat Rev Nephrol. 2012;8(3):132.

9. Hsu CY, McCulloch CE, Darbinian J, Go AS, Iribarren C. Elevated blood pressure and risk of end-stage renal disease in subjects without baseline kidney disease. Arch Intern Med. 2005;165(8):923-928.

10. Kannel WB. Risk stratification in hypertension: new insights from the Framingham Study. Am J Hypertens. 2000;13(1 Pt 2):3S-10S.

11. Bell EK, Gao L, Judd S, et al. Blood pressure indexes and end-stage renal disease risk in adults with chronic kidney disease. Am J Hypertens. 2012;25(7):789-796.

12. Bakris GL, Weir MR, Shanifar S, et al; for RENAAL Study Group Effects of blood pressure level on progression of diabetic nephropathy: results from the RENAAL study. Arch Intern Med. 2003;163(13): $1555-1565$.

13. Ogden LG, He J, Lydick E, Whelton PK. Long-term absolute benefit of lowering blood pressure in hypertensive patients according to the JNC VI risk stratification. Hypertension. 2000;35(2):539-543.

14. Sarafidis PA, Georgianos P, Bakris GL. Resistant hypertension - its identification and epidemiology. Nat Rev Nephrol. 2012;9(1):51-58

15. Persell SD. Prevalence of resistant hypertension in the United States, 2003-2008. Hypertension. 2011;57(6):1076-1080.

16. Erdine S. How do compliance, convenience, and tolerability affect blood pressure goal rates? Am J Cardiovasc Drugs. 2012;12(5):295-302.

17. Marshall IJ, Wolfe CD, McKevitt C. Lay perspectives on hypertension and drug adherence: systematic review of qualitative research. $B M J$. 2012;345:e3953.

18. Roark RF, Shah BR, Udayakumar K, Peterson ED. The need for transformative innovation in hypertension management. Am Heart $J$. 2011;162(3):405-411.

19. Krakoff LR. Systems for care of hypertension in the United States. J Clin Hypertens (Greenwich). 2006;8(6):420-426.

20. Jolles EP, Clark AM, Braam B. Getting the message across: opportunities and obstacles in effective communication in hypertension care. J Hypertens. 2012;30(8):1500-1510.

21. Okonofua EC, Simpson KN, Jesri A, Rehman SU, Durkalski VL, Egan BM. Therapeutic inertia is an impediment to achieving the Healthy People 2010 blood pressure control goals. Hypertension. 2006;47(3): 345-351.

22. Chobanian AV, Bakris GL, Black HR, et al; for National Heart, Lung, and Blood Institute Joint National Committee on Prevention, Detection, Evaluation, and Treatment of High Blood Pessure, National High Blood Pressure Education Program Coordinating Committee. The Seventh Report of the Joint National Committee on Prevention, Detection, Evaluation, and Treatment of High Blood Pressure: the JNC 7 report. JAMA. 2003;289(19):2560-2572.

23. Gradman AH. Rationale for triple-combination therapy for management of high blood pressure. J Clin Hypertens (Greenwich). 2010; 12(11):869-878.
24. Lithell H, Hansson L, Skoog I, et al; for SCOPE Study Group. The Study on Cognition and Prognosis in the Elderly (SCOPE): principal results of a randomized double-blind intervention trial. $J$ Hypertens. 2003;21(5):875-886.

25. Pepine CJ, Handberg EM, Cooper-DeHoff RM, et al; for INVEST Investigators. A calcium antagonist vs a non-calcium antagonist hypertension treatment strategy for patients with coronary artery disease. The International Verapamil-Trandolapril Study (INVEST): a randomized controlled trial. JAMA. 2003;290(21):2805-2816.

26. Wright JT Jr, Dunn JK, Cutler JA, et al; for ALLHAT Collaborative Research Group. Outcomes in hypertensive black and nonblack patients treated with chlorthalidone, amlodipine, and lisinopril. JAMA. 2005; 293(13): 1595-1608.

27. Jamerson K, Weber MA, Bakris GL, et al; for ACCOMPLISH Trial Investigators. Benazepril plus amlodipine or hydrochlorothiazide for hypertension in high-risk patients. $N$ Engl J Med. 2008;359(23): 2417-2428.

28. Black HR. Triple fixed-dose combination therapy: back to the past Hypertension. 2009;54(1):19-22.

29. Hobbs LF. A broad ranged antihypertensive combination (Ser-Ap-Es) Va Med Mon (1918). 1963;90:28-30.

30. Law MR, Wald NJ, Morris JK, Jordan RE. Value of low dose combination treatment with blood pressure lowering drugs: analysis of 354 randomised trials. BMJ. 2003;326(7404):1427.

31. van Zwieten PA, Farsang C. Combination of antihypertensive drugs from a historical perspective. Blood Press. 2005;14(2):72-79.

32. Panjabi S, Lacey M, Bancroft T, Cao F. Treatment adherence, clinical outcomes, and economics of triple-drug therapy in hypertensive patients. J Am Soc Hypertens. 2013;7(1):46-60.

33. Weber MA, Julius S, Kjeldsen SE, et al. Blood pressure dependent and independent effects of antihypertensive treatment on clinical events in the VALUE Trial. Lancet. 2004;363(9426):2049-2051.

34. Feldman RD, Zou GY, Vandervoort MK, Wong CJ, Nelson SA, Feagan BG. A simplified approach to the treatment of uncomplicated hypertension: a cluster randomized, controlled trial. Hypertension. 2009;53(4):646-653.

35. Mason RP, Marche P, Hintze TH. Novel vascular biology of thirdgeneration L-type calcium channel antagonists: ancillary actions of amlodipine. Arterioscler Thromb Vasc Biol. 2003;23(12):2155-2163.

36. Preston Mason R. Pleiotropic effects of calcium channel blockers. Curr Hypertens Rep. 2012;14(4):293-303.

37. Phillips JE, Preston Mason R. Inhibition of oxidized LDL aggregation with the calcium channel blocker amlodipine: role of electrostatic interactions. Atherosclerosis. 2003;168(2):239-244.

38. Witztum JL. The oxidation hypothesis of atherosclerosis. Lancet 1994;344(8925):793-795.

39. Steinberg D. Low density lipoprotein oxidation and its pathobiological significance. J Biol Chem. 1997;272(34):20963-20966.

40. Mason RP. Mechanisms of plaque stabilization for the dihydropyridine calcium channel blocker amlodipine: review of the evidence. Atherosclerosis. 2002;165(2):191-199.

41. Nissen SE, Tuzcu EM, Libby P, et al; for CAMELOT Investigators. Effect of antihypertensive agents on cardiovascular events in patients with coronary disease and normal blood pressure: the CAMELOT study: a randomized controlled trial. JAMA. 2004;292(18): 2217-2225.

42. Toma L, Stancu CS, Sanda GM, Sima AV. Anti-oxidant and antiinflammatory mechanisms of amlodipine action to improve endothelial cell dysfunction induced by irreversibly glycated LDL. Biochem Biophysi Res Commun. 2011;411(1):202-207.

43. Report of the Joint National Committee on Detection, Evaluation, and Treatment of High Blood Pressure. A cooperative study. JAMA 1977;237(3):255-261.

44. Tziomalos K, Athyros VG, Mikhailidis DP, Karagiannis A. Hydrochlorothiazide vs chlorthalidone as the optimal diuretic for the management of hypertension. Curr Pharm Des. Epub December 26, 2012 
45. Lund BC, Ernst ME. The comparative effectiveness of hydrochlorothiazide and chlorthalidone in an observational cohort of veterans. J Clin Hypertens (Greenwich). 2012;14(9):623-629.

46. Roush GC, Holford TR, Guddati AK. Chlorthalidone compared with hydrochlorothiazide in reducing cardiovascular events: systematic review and network meta-analyses. Hypertension. 2012;59(6):1110-1117.

47. DiNicolantonio JJ. Hydrochlorothiazide: is it a wise choice? Expert Opin Pharmacother. 2012;13(6):807-814.

48. Jadhav M, Yeola C, Zope G, Nabar A. Aliskiren, the first direct renin inhibitor for treatment of hypertension: the path of its development. J Postgrad Med. 2012;58(1):32-38.

49. Wood JM, Maibaum J, Rahuel J, et al. Structure-based design of aliskiren, a novel orally effective renin inhibitor. Biochem Biophys Res Commun. 2003;308(4):698-705.

50. Angeli F, Reboldi G, Mazzotta G, et al. Safety and efficacy of aliskiren in the treatment of hypertension and associated clinical conditions. Curr Drug Saf. 2012;7(1):76-85.

51. Powers BJ, Coeytaux RR, Dolor RJ, et al. Updated report on comparative effectiveness of ACE inhibitors, ARBs, and direct renin inhibitors for patients with essential hypertension: much more data, little new information. J Gen Intern Med. 2012;27(6):716-729.

52. Chen Y, Meng L, Shao H, Yu F. Aliskiren vs other antihypertensive drugs in the treatment of hypertension: a meta-analysis. Hypertens Res. 2013;36(3):252-261.

53. Musini VM, Fortin PM, Bassett K, Wright JM. Blood pressure lowering efficacy of renin inhibitors for primary hypertension. Cochrane Database Syst Rev. 2008;4:CD007066.

54. Verdecchia P, Angeli F, Mazzotta G, et al. Aliskiren versus ramipril in hypertension. Ther Adv Cardiovasc Dis. 2010;4(3):193-200.

55. Gao D, Ning N, Niu X, Wei J, Sun P, Hao G. Aliskiren vs angiotensin receptor blockers in hypertension: meta-analysis of randomized controlled trials. Am J Hypertens. 2011;24(5):613-621.

56. Gaddam KK, Oparil S. Renin inhibition: should it supplant ACE inhibitors and ARBS in high risk patients? Curr Opin Nephrol Hypertens. 2008;17(5):484-490.

57. Gerc V, Buksa M, Loza V, Kulic M. Is aliskiren superior to inhibitors of angiotensin-converting enzyme and angiotensin receptor blockers in renin-angiotensin system blockade? Med Arh. 2009;63(6): 343-349.

58. Hollenberg NK, Fisher ND, Price DA. Pathways for angiotensin II generation in intact human tissue: evidence from comparative pharmacological interruption of the renin system. Hypertension. 1998;32(3):387-392.

59. Wolny A, Clozel JP, Rein J, et al. Functional and biochemical analysis of angiotensin II-forming pathways in the human heart. Circ Res. 1997;80(2):219-227.

60. Bomback AS, Klemmer PJ. The incidence and implications of aldosterone breakthrough. Nat Clin Pract Nephrol. 2007;3(9):486-492.

61. ONTARGET Investigators, Yusuf S, Teo KK, Poque J, et al. Telmisartan, ramipril, or both in patients at high risk for vascular events. $N$ Engl $J$ Med. 2008;358(15):1547-1559.

62. Parving HH, Brenner BM, McMurray JJ, et al, ALTITUDE Investigators. Cardiorenal end points in a trial of aliskiren for type 2 diabetes. N Engl J Med. 2012;367(23):2204-2213.

63. Neutel JM, Smith DH. Hypertension management: rationale for triple therapy based on mechanisms of action. Cardiovasc Ther. Epub November 2, 2012.

64. Philipp T, Smith TR, Glazer R, et al. Two multicenter, 8-week, randomized, double-blind, placebo-controlled, parallel-group studies evaluating the efficacy and tolerability of amlodipine and valsartan in combination and as monotherapy in adult patients with mild to moderate essential hypertension. Clin Ther. 2007;29(4):563-580.

65. Pool JL, Glazer R, Weinberger M, Alvarado R, Huang J, Graff A. Comparison of valsartan/hydrochlorothiazide combination therapy at doses up to $320 / 25 \mathrm{mg}$ versus monotherapy: a double-blind, placebocontrolled study followed by long-term combination therapy in hypertensive adults. Clin Ther. 2007;29(1):61-73.
66. Judd E, Jaimes EA. Aliskiren, amlodipine and hydrochlorothiazide triple combination for hypertension. Expert Rev Cardiovasc Ther. 2012;10(3):293-303.

67. Murray AV, Koenig W, Garcia-Puig J, Patel S, Uddin A, Zhang J. Safety and efficacy of aliskiren/amlodipine/hydrochlorothiazide triple combination in patients with moderate to severe hypertension: a 54-week, open-label study. J Clin Hypertens (Greenwich). 2012; 14(12):821-827.

68. Fogari R, Zoppi A, Mugellini A, et al. Effect of aliskiren addition to amlodipine on ankle edema in hypertensive patients: a threeway crossover study. Expert Opin Pharmacother. 2011;12(9): 1351-1358.

69. Chrysant SG, Melino M, Karki S, Lee J, Heyrman R. The combination of olmesartan medoxomil and amlodipine besylate in controlling high blood pressure: $\mathrm{COACH}$, a randomized, double-blind, placebocontrolled, 8-week factorial efficacy and safety study. Clin Ther. 2008;30(4):587-604.

70. Brown MJ, McInnes GT, Papst CC, Zhang J, MacDonald TM. Aliskiren and the calcium channel blocker amlodipine combination as an initial treatment strategy for hypertension control (ACCELERATE): a randomised, parallel-group trial. Lancet. 2011;377(9762): 312-320.

71. Chrysant SG, Murray AV, Hoppe UC, et al. Long-term safety and efficacy of aliskiren and valsartan combination with or without the addition of HCT in patients with hypertension. Curr Med Res Opin. 2010;26(12):2841-2849.

72. Stergiou GS, Makris T, Papavasiliou M, Efstathiou S, Manolis A. Comparison of antihypertensive effects of an angiotensin-converting enzyme inhibitor, a calcium antagonist and a diuretic in patients with hypertension not controlled by angiotensin receptor blocker monotherapy. J Hypertens. 2005;23(4):883-889.

73. Volpe M, Brommer P, Haag U, Miele C. Efficacy and tolerability of olmesartan medoxomil combined with amlodipine in patients with moderate to severe hypertension after amlodipine monotherapy: a randomized, double-blind, parallel-group, multicentre study. Clin Drug Investig. 2009;29(1):11-25.

74. Mancia G, Laurent S, Agabiti-Rosei E, et al; for European Society of Hypertension. Reappraisal of European guidelines on hypertension management: a European Society of Hypertension Task Force document. J Hypertens. 2009;27(11):2121-2158.

75. Lacourcière $\mathrm{Y}$, Taddei $\mathrm{S}$, Konis G, Fang H, Severin T, Zhang J. Clinic and ambulatory blood pressure lowering effect of aliskiren/amlodipine/ hydrochlorothiazide combination in patients with moderate-to-severe hypertension: a randomized active-controlled trial. J Hypertens. 2012;30(10):2047-2055.

76. Ferdinand KC, Weitzman R, Israel M, Lee J, Purkayastha D, Jaimes EA. Efficacy and safety of aliskiren-based dual and triple combination therapies in US minority patients with stage 2 hypertension. J Am Soc Hypertens. 2011;5(2):102-113.

77. Ferdinand KC, Weitzman R, Purkayastha D, Sridharan K, Jaimes EA. Aliskiren-based dual- and triple-combination therapies in high-risk US minority patients with stage 2 hypertension. JAm Soc Hypertens. 2012; 6(3):219-227.

78. Villamil A, Chrysant SG, Calhoun D, et al. Renin inhibition with aliskiren provides additive antihypertensive efficacy when used in combination with hydrochlorothiazide. J Hypertens. 2007;25(1):217-226.

79. Lijnen P, Fagard R, Staessen J, Amery A. Effect of chronic diuretic treatment on the plasma renin-angiotensin-aldosterone system in essential hypertension. Br J Clin Pharmacol. 1981;12(3):387-392.

80. O'Brien E, Barton J, Nussberger J, et al. Aliskiren reduces blood pressure and suppresses plasma renin activity in combination with a thiazide diuretic, an angiotensin-converting enzyme inhibitor, or an angiotensin receptor blocker. Hypertension. 2007;49(2): 276-284.

81. Duggan ST, Chwieduk CM, Curran MP. Aliskiren: a review of its use as monotherapy and as combination therapy in the management of hypertension. Drugs. 2010;70(15):2011-2049. 
82. Oparil S, Yarows SA, Patel S, Fang H, Zhang J, Satlin A. Efficacy and safety of combined use of aliskiren and valsartan in patients with hypertension: a randomised, double-blind trial. Lancet. 2007;370(9583): 221-229.

83. Uresin Y, Taylor AA, Kilo C, et al. Efficacy and safety of the direct renin inhibitor aliskiren and ramipril alone or in combination in patients with diabetes and hypertension. J Renin Angiotensin Aldosterone Syst. 2007;8(4):190-198.

84. Schmieder RE, Philipp T, Guerediaga J, et al. Long-term antihypertensive efficacy and safety of the oral direct renin inhibitor aliskiren: a 12-month randomized, double-blind comparator trial with hydrochlorothiazide. Circulation. 2009;119(3):417-425.

85. Kushiro T, Itakura H, Abo Y, Gotou H, Terao S, Keefe DL. Long-term safety, tolerability, and antihypertensive efficacy of aliskiren, an oral direct renin inhibitor, in Japanese patients with hypertension. Hypertens Res. 2009;32(3):169-175.
86. Duprez DA, Munger MA, Botha J, Keefe DL, Charney AN. Aliskiren for geriatric lowering of systolic hypertension: a randomized controlled trial. J Hum Hypertens. 2010;24(9):600-608.

87. Littlejohn TW 3rd, Trenkwalder P, Hollanders G, Zhao Y, Liao W. Long-term safety, tolerability and efficacy of combination therapy with aliskiren and amlodipine in patients with hypertension. Curr Med Res Opin. 2009;25(4):951-959.

88. Toh S, Reichman ME, Houstoun M, et al. Comparative risk for angioedema associated with the use of drugs that target the reninangiotensin-aldosterone system. Arch Intern Med. 2012;172(20): $1582-1589$.

89. de la Sierra A. Mitigation of calcium channel blocker-related oedema in hypertension by antagonists of the renin-angiotensin system. J Hum Hypertens. 2009;23(8):503-511.

\section{Publish your work in this journal}

Integrated Blood Pressure Control is an international, peer-reviewed open-access journal focusing on the integrated approach to managing hypertension and risk reduction. Treating the patient and comorbidities together with diet and lifestyle modification and optimizing healthcare resources through a multidisciplinary team approach constitute key

\section{Dovepress}

features of the journal. This journal is indexed on American Chemical Society's Chemical Abstracts Service (CAS). The manuscript management system is completely online and includes a very quick and fair peerreview system, which is all easy to use. Visit http://www.dovepress.com/ testimonials.php to read real quotes from published authors.

Submit your manuscript here: http://www.dovepress.com/integrated-blood-pressure-control-journal 